\title{
Gestão da Inovação na Administração Pública Federal: reflexões sobre os caminhos, as barreiras e as perspectivas
}

\author{
Innovation Management in the Public Sector: reflections on the ways, \\ barriers and perspectives of innovation within the federal public \\ administration
}

\author{
Bartolomeu das Neves Marques ${ }^{1}$ \\ Ângela Maria Ferreira Lima ${ }^{1}$ \\ André Luis Rocha de Souza ${ }^{1}$ \\ Marcio Luis Valença Araújo ${ }^{1}$ \\ ${ }^{1}$ Instituto Federal da Bahia, Salvador BA, Brasil
}

\begin{abstract}
Resumo
Para atender aos interesses da população, o setor público brasileiro vem implementando práticas inovadoras para o enfrentamento das limitações. Este estudo pretende refletir sobre os caminhos, barreiras e perspectivas da implementação da inovação no serviço público federal. A metodologia seguiu a abordagem qualitativa, exploratória e bibliográfica, por meio de pesquisas em periódicos e de consultas a sites especializados como fontes secundárias, além de documentos disponibilizados em sites oficiais. Observou-se que existe a necessidade de adoção pelo governo federal de abordagem sistêmica da inovação e de implementação da inovação organizacional nas suas instituições. Sugere-se a ampliação da participação de órgãos e de empresas no concurso Inovação no Serviço Público Federal, promovido pela Escola Nacional de Administração Pública, a realização de novas pesquisas para identificação de modelos adequados de gestão da inovação no âmbito público federal e do envolvimento de dirigentes para a cultura da inovação. O trabalho está dividido em seis seções, faz uma abordagem mais genérica acerca da inovação e das teorias relacionadas até delimitar a Administração Pública Federal.
\end{abstract}

Palavras-chave: Gestão da Inovação. Inovação. Setor Público.

\begin{abstract}
To meet the interests of the population, the Brazilian public sector has been implementing innovative practices to address limitations. This study aimed to reflect on the ways, barriers and perspectives of the implementation of innovation in the federal public service. The methodology followed the qualitative, exploratory and bibliographical approach, through research in journals and consultations with specialized websites as secondary sources, as well as documents available on official websites. It was observed that there is a need for the federal government to adopt the systemic approach to innovation and the implementation of organizational innovation in its institutions. It is suggested to increase the participation of agencies and companies in the Innovation in the Federal Public Service competition, promoted by the National School of Public Administration, to carry out new researches to identify appropriate models of innovation management in the federal public sphere and the involvement of leaders for the culture of innovation. The paper is divided into six sections, bringing a more general approach to innovation and related theories until it delimits the Federal Public Administration.
\end{abstract}

Keywords: Innovation Management. Innovation. Public Sector.

Área Tecnológica: Inovação. Gestão da Inovação. 


\section{Introdução}

Historicamente, o ciclo da inovação no mundo pode ser dividido em três etapas. A primeira compreendendo o conceito como invenção, desde o início da humanidade; a segunda relacionada à imitação, em mercados que têm como base a produção e a terceirização de produtos de consumo; e a terceira em posição estratégica para a sustentabilidade dos negócios no século XXI. A divisão didática da inovação em ciclos acompanha a perspectiva histórica da evolução do modelo capitalista (SANTOS; FAZION; MEROE, 2011).

Estrategicamente, o conhecimento é um dos recursos mais significativos para as empresas. Esse conhecimento não é considerado sob o ponto de vista fechado de uma organização, mas é capaz de promover o intercâmbio entre essas organizações, apesar de ele ser geralmente referido como a transferência de conhecimento de uma entidade para outra (OCDE, 2018a).

A inovação precisa trazer consigo uma mudança e, em seu contexto, deve se apresentar como uma novidade. É necessário que represente uma novidade ao contexto aplicado. Nesse sentido, o Manual de Oslo, quarta edição, considera, de maneira geral, que a inovação se refere a um novo produto ou processo para a unidade institucional, ou seu aprimoramento, introduzindo significativamente diferenciação dos produtos e processos anteriores (OCDE, 2018a).

Parece contraditória a afirmação, mas "pouca coisa é de fato nova em inovação" (KEELEY et al., 2015, p. 5), isso quer dizer que a maioria das inovações está baseada em conhecimentos e em avanços anteriores. E, justamente, não é imperativo que essas inovações se apresentem como uma novidade para o mundo, mas para um mercado ou setor. E, por fim, as inovações precisam de viabilidade, ou seja, devem retornar um valor para o indivíduo ou empreendimento. Diante das compreensões e das discussões apresentadas, segundo esses autores, entende-se por inovação "a criação de uma oferta nova e viável" (KEELEY et al., 2015).

Mesmo em períodos que o mercado se mostrava, comumente, menos mutável, a inovação já era considerada como uma fonte de modificação do consumo com práticas impulsionadas pelos produtores, ou seja, de dentro das empresas para o mercado. Os consumidores podiam ser influenciados por novidades e podiam desejar novos produtos e serviços, rompendo a ideia de apenas buscar o atendimento de suas necessidades. Até mesmo para produzir as mesmas coisas, a mudança poderia advir de combinações de antigos processos com a inserção de ajustes, gerando combinações novas (SCHUMPETER, 1934).

Por se tratar de uma teoria do desenvolvimento econômico, em um olhar menos atento, pode-se restringir a inovação trazida por Schumpeter ao mercado privado, entretanto, não se dissocia o Estado de sua participação na economia e, muitas vezes, como explorador de atividades econômicas. Cavalcante e Cunha (2017) ressaltam que essa teoria aplicada à inovação no serviço público não retira o seu caráter schumpeteriano, uma vez que não anula a essência do seu direcionamento para a lucratividade do mercado privado, tampouco retira do Estado o seu caráter principal de atendimento aos interesses coletivos.

A administração pública enfrenta a dificuldade em compatibilizar o atendimento para as necessidades sociais, que é papel do Estado, com a escassez de recursos. A inovação no setor público tem o papel de apoiar o direcionamento da administração ao atendimento dos interesses da sociedade, principalmente com a modernização da gestão pública (PEDROSA, 2019). 
As raízes históricas das inovações no setor são mais fortemente presentes na reforma gerencial brasileira, década de 1990, com tentativas de o Estado utilizá-las em práticas das empresas privadas para impulsionar sua eficiência. Entretanto, há críticas de estudiosos da área sobre o modelo, destacando as limitações, especialmente, as relacionadas aos aspectos legais e à falta da discricionariedade dos administradores para a tomada de decisões (NETO, 2010).

Diante dessas críticas e, também, considerando que o setor público brasileiro ainda tem o modelo gerencial como norteador da gestão, tem-se como problema de pesquisa: quais as barreiras à inovação no serviço público federal brasileiro e quais caminhos devem ser seguidos para a implementação da inovação e sua gestão?

A partir do problema levantado, o estudo pretende realizar uma reflexão sobre os caminhos, as barreiras e as perspectivas acerca da implementação da inovação no âmbito do serviço público federal.

Este estudo aborda a inovação no setor público com enfoque da Administração Pública Federal, elencando barreiras para a prática da inovação, além de questionar e discutir a inovação com base em estudos da área. Sua contribuição está em discutir essas barreiras e, também, as possibilidades para a sua implementação. A interlocução de variadas pesquisas na área permitiu análises e discussões que incentivam a reflexão para novas aplicações, que envolvem governo, organizações públicas e o corpo diretivo das instituições públicas federais. Essa abordagem permitiu que a análise abarcasse o âmbito interno e externo das organizações públicas e o meio político.

O artigo está dividido em seis seções que abarcam a introdução, a metodologia, o referencial teórico, com resultados e discussões, e as considerações finais. A primeira seção se dedica a apresentar ao leitor uma abordagem mais conceitual da inovação; a segunda explica o percurso metodológico para o desenvolvimento do trabalho; o referencial teórico e as discussões levantadas estão distribuídas em três seções; e, por fim, as considerações finais apresentam o fechamento do estudo e algumas proposições para novas pesquisas.

\section{Metodologia}

De modo a responder ao questionamento sobre quais barreiras podem refletir na implementação da inovação no âmbito do serviço público federal, este estudo teve como objetivo analisar as barreiras que podem impactar a implementação da inovação no serviço público federal brasileiro. Essas barreiras foram identificadas tanto em nível institucional quanto governamental. Para viabilizar o objetivo, foram utilizadas literaturas, pesquisas e documentos oficiais, tanto sob a ótica do Brasil quanto a de outros países.

Para a busca de periódicos acerca do tema foi utilizada a base Scopus, selecionando-se documentos dos últimos dez anos disponíveis em acesso aberto.

Como critério de seleção dos artigos, foram excluídos aqueles que não apresentavam no seu título ou resumo qualquer menção aos termos "gestão" e assemelhados, "inovação" ou "pública" e variações. De igual forma, o critério de inclusão levou em consideração os artigos que apresentavam um desses termos. 
Foram selecionadas, também, outras literaturas de suporte teórico como livros e documentos oficiais. A partir da definição do escopo da literatura, estruturou-se o estudo desde a visão em outros países até centrar a sua visão na Administração Pública Federal no Brasil.

A pesquisa tem natureza qualitativa, exploratória e bibliográfica e está caracterizada como um ensaio teórico no qual foram realizadas discussões com base em diferentes fontes, de modo a evidenciar a inovação no serviço público e suas barreiras. Foi possível relacionar o caso brasileiro com outros países e dialogar com as necessidades de superação desses entraves com os autores estudados.

\section{Resultados e Discussão}

Nesta seção serão apresentadas as abordagens que contribuem para a discussão acerca da inovação nas organizações e, também, em âmbito governamental. Com base nos estudos utilizados, apresenta-se a inovação em suas múltiplas perspectivas, ultrapassando a visão que a coloca apenas voltada para novos produtos e/ou serviços, especialmente passíveis de proteção. Assim, aborda-se desde a importância de pequenas iniciativas no interior das organizações até a esfera de governo, destacando-se as barreiras que impõem desafios ao serviço público na prática da inovação.

\subsection{Inovação: adoção e prática}

Atualmente, o meio dos negócios vê a inovação como forma de resolver problemas empresariais, desde problemas mercadológicos até os motivacionais. Por outro lado, pessoas são influenciadas ao apelo dos atributos de produtos e serviços adjetivados como inovadores, contudo, sem necessariamente compreenderem o que venha a ser isso. A visão quase unânime de empresários e de consumidores é de que a inovação é um sinal positivo para organizações, bens e serviços (PLONSKI, 2017).

A inovação deve ser vista como um processo e não de forma isolada. Assim, a inovação precisa ser gerida e envolver os diferentes níveis da organização, inclusive para a escolha dos métodos mais adequados de customização para a realidade desejada. O seu desenvolvimento envolve decisão de gestão sobre métodos, recursos materiais e humanos a serem disponibilizados para sua prática, devendo ser incorporada à cultura e sendo importante comunicar na missão (KENSKI, 2011).

\subsubsection{Inovação Organizacional}

A inovação organizacional foi introduzida na terceira edição do Manual de Oslo (OCDE, 2006). As inovações tecnológicas de produto e de processo foram trazidas na primeira e segunda edições e tinha forte relação com organizações estudadas e integrantes de países desenvolvidos pertencentes à Organização para Cooperação e Desenvolvimento Econômico (OCDE). Com as possibilidades de aplicações de conceitos gerais e de experiências para a realidade de países menos desenvolvidos e a adaptação a outros contextos organizacionais, o documento foi atualizado e considerou as inovações de marketing e organizacional. Em síntese, essas inovações são definidas como: 
Uma inovação de produto é a introdução de um bem ou serviço novo ou significativamente melhorado no que concerne a suas características ou usos previstos [...] Uma inovação de processo é a implementação de um método de produção ou distribuição novo ou significativamente melhorado [...] Uma inovação de marketing é a implementação de um novo método de marketing com mudanças significativas na concepção do produto ou em sua embalagem, no posicionamento do produto, em sua promoção ou na fixação de preços [...] Uma inovação organizacional é a implementação de um novo método organizacional nas práticas de negócios da empresa, na organização do seu local de trabalho ou em suas relações externas [...]. (OCDE, 2006, p. 57-61)

Essa atualização contribuiu para ampliar o conceito de inovação e sua consequente aplicação em ambientes com menor uso de tecnologias e investimentos em Pesquisa e Desenvolvimento (P\&D), a exemplo da indústria de serviços. Além disso, foram inseridos casos de pesquisas na área em países fora da Organização para Cooperação e Desenvolvimento Econômico (OCDE, 2006).

A inovação para uma organização não se limita à introdução de tecnologia, uma vez que esta, de forma isolada e sem envolvimento para adaptação ao novo, não gera competitividade. Pois, mais difícil do que inserir novas tecnologias aos negócios, é promover as mudanças organizacionais necessárias para a adaptação e a compreensão de seus impactos no âmbito de sua atuação (TIGRE, 2006).

É nesse sentido que se concentra o grande desafio: mudar e permitir alterações que podem incluir mudanças nos níveis de autoridade e, com isso, impactar nas relações de poder e até revisar atividades e rotinas cristalizadas. Assim, quanto menos flexível e aberta for a organização, maior será a dificuldade para se beneficiar da inovação, tornando-se necessário o rompimento de práticas tradicionais para substitui-las por novas práticas organizacionais (TIGRE, 2006).

Nas organizações contemporâneas, a inovação se apresenta aos gestores como um dilema quando é preciso definir se deve ser incremental e/ou de ruptura, pois muitas grandes empresas falharam ao não se lançar em novos mercados e realizar melhorias somente com base nas atuais tecnologias (CHRISTENSEN, 2012).

Os estudos que se dedicam às reflexões acerca da gestão da inovação têm como principal centro de observação as empresas de grande porte, com processos estruturados de $\mathrm{P} \& \mathrm{D}$, ciclos de desenvolvimento de médio ou longo prazos. Há um predomínio de casos que destacam a tecnologia, as relações com o mercado consumidor e a tangibilidade dos produtos como elementos mais ligados à inovação (SILVA et al., 2014).

Ampliando a visão da inovação das grandes estruturas de P\&D para abarcar estruturas menores e até simples, é possível gerar inovações organizacionais a partir das ideias de todos os colaboradores.

Os autores pesquisaram ${ }^{1}$ inúmeras empresas com práticas orientadas para as ideias e observaram, como resultado, ganhos importantes no desempenho. Eles ressaltam que organizações tradicionais são dirigidas e movidas pelo topo, já as organizações movidas por ideias continuam com a direção em alto nível, mas com ideias vindas de outros níveis hierárquicos com menor poder de decisão (ROBINSON; SCHROEDER, 2016).

\footnotetext{
${ }^{1}$ A pesquisa teve como técnica a investigação de organizações com os processos que as orientavam para as ideias, aprofundando-se na observação, quase em tempo real, dos contextos operacionais e de outras organizações em nível inicial de implantação. Buscou-se a compreensão do que funcionava e do que não funcionava e foram aplicadas as experiências observadas e refinadas em outras organizações por meio de consultoria junto a líderes e gestores, gerando conceitos e recomendações contidas na obra dos autores.
} 
É repetitivo e defasado para as organizações focarem apenas em reduzir custos, fazendo com que as pessoas produzam cada vez mais com menos recursos. As organizações precisam ir além dessa postura reducionista para atender a demandas adicionais do mercado e do negócio, já que, justamente, as pessoas impactadas na linha de frente com essa perspectiva reducionista são aquelas que irão promover as melhores soluções para tornar mais efetivo o ambiente de inovação (ROBINSON; SCHROEDER, 2016).

\subsection{A Organização Criadora}

A gestão do conhecimento enxerga a organização em sua totalidade, considerando pessoas e áreas especializadas em suas múltiplas interações. A organização criadora é capaz de acompanhar mudanças e de se manter sustentável mesmo diante da forte concorrência e da obsolescência rápida de muitos produtos e serviços, uma vez que o seu principal recurso é o conhecimento (TAKEUCHI; NONAKA, 2008).

Criar novos conhecimentos significa recriar a empresa e todos nela em um processo de autorrenovação pessoal e organizacional ininterrupto. Nesse ambiente, o novo conhecimento não é uma atividade especializada, mas uma forma de comportamento, na qual todos são trabalhadores do conhecimento - isto é, empreendedores (NONAKA, 2008).

O direcionamento central da abordagem de Nonaka (2008) pode ser relacionado ao trabalho de Robinson e Schroeder (2016), no qual as novas ideias são estimuladas para todos e implementadas dentro da organização, independentemente de especialização ou posição hierárquica. Evidencia-se o impacto da cultura da criação sobre as pessoas, em que todos precisam se envolver e promover o empreendedorismo.

\subsection{Gestão da Inovação na Administração Pública}

A Comissão Europeia (2013, p. 11), em publicação sobre a nova arquitetura do setor público convalidou que "[...] a inovação no setor público pode ser definida como o processo de geração de novas ideias e implementá-los para criar valor para a sociedade [...]" e, ainda, qualquer elemento novo que funcione. O documento registra que os funcionários públicos dos Estados-Membros entendem a inovação no serviço público como novos processos e serviços ou o seu aprimoramento, o primeiro com foco interno e o segundo, externo. Também identifica três objetivos genéricos para a inovação no setor público, que estão alinhados com o entendimento da OCDE: 1 - Foco Interno: aumento da eficiência do setor por meio de políticas e iniciativas internas; 2 - Foco Externo: políticas e iniciativas para gerar valor à sociedade, por meio de melhores serviços e resultados, incluindo as organizações; 3 - Foco em outros setores: políticas $e$ iniciativas que pretendam promover a inovação em outros setores.

Nessa publicação, foram levantadas por um grupo de peritos as barreiras à inovação no contexto da União Europeia (eu) que, em geral, são os fatores facilitadores fracos ou condições estruturais desfavoráveis; falta de liderança em todos os níveis; conhecimento e aplicação limitados de processos e métodos de inovação; uso insuficientemente preciso e sistemático de medições e dados.

A inovação no setor público europeu está atrelada a obstáculos próprios. A governança da inovação carece de uma visão de longo prazo e de reformas. Há dificuldades de aprendizado, 
difusão de boas práticas entre os países membros, inexistência de regulamentação inteligente e administração responsiva, ou seja, há o engessamento dos modelos de gestão e das normas que não promovem a variação e a experimentação. $\mathrm{O}$ uso da tecnologia não acompanha as suas possibilidades para governo eletrônico, mídias sociais e outros. O papel de comprador do governo não é usado para incentivar a inovação. $\mathrm{O}$ capital de risco disponibilizado é pouco expressivo para atrair investidores externos interessados em desenvolver soluções inovadoras para o setor público. Observam-se entraves para aprendizagem organizacional e para as consequentes inovações institucionais, como práticas de recursos humanos, leis, regulamentos e falta de incentivos para a criação e a implementação de novas ideias (COMISSÃO EUROPEIA, 2013).

Uma pesquisa realizada em 2012 com 25 dos 27 Estados-Membros da UE, excetuando-se apenas Chipre e Luxemburgo, com base em entrevista estruturada aplicada a servidores públicos e acadêmicos da área, utilizou-se da metodologia de teoria fundamentada para análise e interpretação dos dados qualitativos. Essa pesquisa resultou no agrupamento do que categorizou como fatores e barreiras para a inovação na União Europeia: fatores internos, externos e políticos (LEÓN; SIMMONDS; ROMAN, 2012). Foram destacados nessa pesquisa as barreiras com maior prevalência, a saber:

a) Internos: recursos humanos, burocracia/design organizacional. O primeiro destaca a educação e o treinamento dos servidores, o esquema de incentivo para a motivação de pessoal, a liderança e a gestão e outros fatores, como a disponibilidade de tempo para se dedicar a recursos humanos e a escassez de pessoal. $\mathrm{O}$ segundo se refere aos processos internos da organização, gestão do desempenho, incluindo acompanhamento e avaliação, cultura interna de inovação.

b) Externos: boas práticas internacionais e transferência de conhecimento, classificações internacionais, prêmios nacionais, cocriação/participação do usuário do serviço/colaboração entre setores público-privado, demandas dos cidadãos e das empresas.

c) Políticos: reduções/restrições orçamentárias; disponibilidade de financiamento/recursos financeiros; decisões políticas da UE (ou seja, fundos da UE)/requisitos a nível da UE; apoio político (mais flexível), leis e regulamentos.

Quando se analisa o setor público apenas sob a égide rígida das normas e dos regulamentos e de tantas limitações, como as apresentadas por León, Simmonds e Roman (2012), parece difícil pensar em inovação no setor, entretanto, não é só possível como é necessário. Foi nesse sentido que Cavalcante e Cunha (2017) desenvolveram um estudo mostrando os impactos das transformações sociais, políticas e econômicas sobre os governos e a necessidade de buscar meios para lidar com essas rápidas mudanças, sendo a inovação uma importante fonte para atuação adaptativa e reativa do Estado.

Os autores destacam que, nos últimos 15 anos considerados no estudo, foi crescente o número de publicações para compreensão da inovação no setor público e suas aplicações, fa- 
zendo parte da agenda de discussão brasileira que debate reforma administrativa e inovação. Esse estudo considerou, ainda, que a inovação na administração pública é necessária diante das falhas notórias de governo, da demanda dos cidadãos por melhores serviços, do controle social e dos problemas complexos da contemporaneidade - como o aquecimento global, a pobreza, a desigualdade social e outros - os chamados wicked-problemas, contudo, destaca-se que a inovação vai além do atendimento a essas demandas.

Em pesquisa realizada por Brandão e Bruno-Faria (2017) acerca das barreiras para a inovação no serviço público federal, na perspectiva de dirigentes, observou-se que as decisões da alta gestão estão ligadas a fatores, muitas vezes, incontroláveis por esses dirigentes, a exemplo dos limites legais e das restrições de recursos. Esse levantamento, exploratório e qualitativo, foi realizado a partir da análise documental de casos premiados no Concurso Inovação da Escola Nacional de Administração Pública (ENAP) e em livros que descrevem tais barreiras, e, como respondentes da pesquisa, a amostra foi composta de dirigentes de diversas organizações federais da administração direta e indireta. Como resultado dessa análise, chegou-se a nove tipos de barreiras:

[...] dificuldade de articulação intersetorial; restrições legais; estrutura organizacional verticalizada; resistência à inovação e aversão ao risco; baixa capacidade técnica dos estados e municípios; rotatividade de dirigentes; diversidade social, cultural e econômica do país; recursos orçamentários e financeiros limitados e falta de incentivos à inovação. (BRANDÃO; BRUNO-FARIA, 2017, p. 161)

Brandão e Bruno-Faria (2017, p. 147), após adaptação conceitual da abordagem de Birkinshaw, Hamel e Mol (2008), consideraram que a "[...] inovação em gestão é a implementação de práticas gerenciais, processos, estruturas ou técnicas que são novas para a unidade adotante e que pretendem potencializar os objetivos organizacionais". Nessa perspectiva de inovação em gestão, as melhorias incrementais e adaptações de práticas geradas ou utilizadas em outros ambientes são, também, consideradas inovação.

A decisão de inovar no âmbito público deve estar acompanhada da avaliação dos riscos, da aderência à missão da organização e, consequentemente, dos impactos sociais da mudança. Pois, considerando a supremacia do interesse público, não basta que uma inovação seja importante apenas para o negócio, já que a decisão de conduzir uma transformação deve vincular-se ao interesse coletivo, sendo importante a verificação das consequências da inovação após a sua implementação (OLIVEIRA; SANTOS JÚNIOR, 2017).

Apresenta-se quadro resumo com as principais barreiras à inovação destacadas nas pesquisas mencionadas nesta seção, além de serem destacados os desafios a serem superados, com base nesses estudos. 
Quadro 1 - Barreiras e Desafios à prática da inovação no setor público

\begin{tabular}{|c|c|c|}
\hline FONTES & FATORES/BARREIRAS À INOVAÇÃO & Principais Desafios \\
\hline $\begin{array}{l}\text { União } \\
\text { Europeia } \\
\text { (2013) }\end{array}$ & $\begin{array}{l}\text { - Fatores facilitadores fracos ou } \\
\text { condições estruturais desfavoráveis; } \\
\text { - Falta de liderança em todos os níveis; } \\
\text { - Conhecimento e aplicação limitados } \\
\text { de processos e métodos de inovação; } \\
\text { - Uso insuficientemente preciso e } \\
\text { sistemático de medições e dados. }\end{array}$ & $\begin{array}{l}\text { - Desenvolver a interlocução de boas } \\
\text { práticas entre os países membros; } \\
\text { - Capacitar lideranças para estimularem } \\
\text { equipes a inovarem; e } \\
\text { - Difusão e implementação de métodos } \\
\text { adequados para análise e interpretação } \\
\text { dos dados relativos à inovação. }\end{array}$ \\
\hline $\begin{array}{l}\text { León, } \\
\text { Simmonds e } \\
\text { Roman }(2012)\end{array}$ & $\begin{array}{l}\text { - Fatores internos, } \\
\text { - Fatores externos; e } \\
\text { - Fatores políticos }\end{array}$ & $\begin{array}{l}\text { - Internos: flexibilidade nos processos para redução } \\
\text { de burocracia e estímulo à gestão de pessoas com } \\
\text { ênfase no desenvolvimento do capital humano; e } \\
\text { - Externos: Intercâmbio de práticas internacionais; } \\
\text { fomentar parcerias público-privadas. }\end{array}$ \\
\hline $\begin{array}{l}\text { Cavalcante e } \\
\text { Cunha (2017) }\end{array}$ & $\begin{array}{l}\text { - Visão da inovação para resolução das } \\
\text { falhas de mercado e de governo. }\end{array}$ & $\begin{array}{l}\text { - Desenvolver a cultura da inovação, de modo } \\
\text { que governo e suas instituições ultrapassem } \\
\text { a visão da inovação em sua perspectiva } \\
\text { reativa, ou seja, apenas para resolução dos } \\
\text { problemas de mercado e de governo. }\end{array}$ \\
\hline $\begin{array}{l}\text { Brandão e } \\
\text { Bruno-Faria } \\
\quad(2017)\end{array}$ & $\begin{array}{l}\text { - Dificuldade de articulação intersetorial; } \\
\text { - Restrições legais; estrutura } \\
\text { organizacional verticalizada; } \\
\text { - Resistência à inovação e } \\
\text { aversão ao risco; } \\
\text { - Baixa capacidade técnica dos } \\
\text { estados e municípios; } \\
\text { - Rotatividade de dirigentes; } \\
\text { - Diversidade social, cultural } \\
\text { e econômica do país; e } \\
\text { - Recursos orçamentários e } \\
\text { financeiros limitados e falta } \\
\text { de incentivos à inovação. }\end{array}$ & $\begin{array}{l}\text { - Realizar intercâmbio de ações } \\
\text { entre setores e organizações; } \\
\text { - Ajustes no design organizacional; } \\
\text { - Fortalecimento da cultura da inovação; } \\
\text { - Interlocução entre políticas de níveis } \\
\text { federal, estadual e municipal; e } \\
\text { - Coordenação de ações entre governo, } \\
\text { universidades, empresas e o terceiro setor, } \\
\text { visando superar as limitações de recursos } \\
\text { e fortalecer iniciativas que beneficiem } \\
\text { os diversos agentes envolvidos. }\end{array}$ \\
\hline $\begin{array}{l}\text { Oliveira e } \\
\text { Santos Júnior } \\
\text { (2017) }\end{array}$ & - Riscos assumidos na decisão de inovar. & $\begin{array}{l}\text { - Orçamentos para ações de inovação } \\
\text { que permitam aos dirigentes assumirem } \\
\text { riscos, com normativos claros acerca da } \\
\text { aderência aos interesses coletivos. }\end{array}$ \\
\hline
\end{tabular}

Fonte: Elaborado pelos autores deste artigo

Nas pesquisas trazidas nesta seção, observa-se que nas abordagens da Comissão Europeia (2013) e de León, Simmonds e Roman (2012) há uma orientação para a discussão da inovação nos âmbitos internos, externos e políticos. Nesse particular, há um diálogo entre os fatores organizacionais, os de mercado, o governo e as políticas públicas relacionadas. Na abordagem de Cavalcante e Cunha (2017), o foco do trabalho é a inovação no contexto governamental. Brandão e Bruno-Faria (2017) enfatizam as barreiras que limitam a inovação nas organizações do setor público, resultando em uma visão mais focada no ambiente interno, e Oliveira e Santos Júnior (2017) discutem, entre outros aspectos, a tomada de decisão e o alinhamento da inovação com a missão dos órgãos públicos em atender ao interesse público.

As visões apresentadas sob enfoque mais generalista ou dedicado mais às questões internas dos órgãos públicos possuem abordagens que se complementam. Além disso, essas visões demonstram que a inovação no setor público deve ser efetivada a partir de um intercâmbio de ações entre instituições públicas, mercado e governo. 
Outro ponto a ser destacado é que mesmo na esfera da UE foram verificadas, entre outras, barreiras relacionadas à capacidade técnica, burocracia, estrutura/design organizacional, restrições legais e orçamentárias, assim como o que foi apontado pelas pesquisas brasileiras.

\subsection{Inovação no Setor Público Federal Brasileiro}

A Nova Gestão Pública (NGP) foi um modelo de reforma administrativa do aparelho do Estado implementada pela maioria dos países no mundo, e, mais fortemente, nas últimas três décadas e foi influenciada pela busca da aplicação das práticas da gestão privada no setor público. A NGP tem como alicerce a profissionalização, a redução da burocracia, a melhor prestação de serviços aos cidadãos, a melhoria no desempenho e, consequentemente, a maior eficiência nas ações do governo. As inovações perseguidas pelos países com NGP não foram bem-sucedidas em todos os países e muitos sofreram com o enfraquecimento do governo $e$ com as dificuldades dos órgãos em servir à população, devido a uma maior complexidade da máquina pública (BOWREY; HUI; SMARK, 2017; CASETTI, 2014).

O tema já era debatido no governo britânico no início do século XIX por dois nomes de influência política e com conhecimento técnico do serviço público - Parnel e Bentham. Parnel defendia o fomento à indústria, a redução de impostos e do papel do Estado e a terceirização de atividades. Bentham contrapôs-se, em muitos momentos, a Parnel destacando a necessidade de observar o atendimento ao interesse público e as particularidades do setor privado em relação ao público nas decisões de adotar práticas desse mercado. Assim, as propostas de reformas administrativas com base em modelo gerencial não são algo tão novo quanto possa parecer (BOWREY; HUI; SMARK, 2017).

No final dos anos de 1990, a discussão acerca de uma nova gestão pública era uma agenda para toda a América Latina e, naquela oportunidade, países europeus já apresentavam avanços na aplicação da administração gerencial. O objetivo era definir uma reforma aderente à realidade dos países latino-americanos para ações de redemocratização e de desenvolvimento social e econômico, por meio da eficiência da máquina pública e da governança do Estado (CLAD, 1998).

Os países que foram mais adiante na reforma da gestão pública são Grã-Bretanha, Nova Zelândia, Austrália, todos os países escandinavos, Estados Unidos, Brasil e Chile. A Itália está profundamente engajada na reforma; na França e Alemanha algum movimento pode ser visto nesta direção, mas a administração permanece essencialmente burocrática. Embora incluíssemos dois países latino-americanos na lista acima, a maioria dos países nesta região nem mesmo empreendeu uma reforma do serviço público. (BRESSER-PEREIRA, 2002, p. 7)

No caso do Chile, o processo de modernização da gestão pública de 1990 a 2010 teve como objetivo inicial retomar a capacidade operativa do Estado (1990-1994), dar ênfase à eficiência e aos resultados (1994-2000), criar instituições eficientes e flexíveis (2000-2006), gerar excelência no serviço às pessoas (2006-2010) (CASETTI, 2014). 
Destacam-se no Brasil a mudança da concepção de gestão pública e a orientação para novas práticas com a reforma gerencial, implementadas no país na década de 1990. Esse modelo buscou substituir o modelo burocrático e aplicar as práticas das empresas privadas, com intuito de melhorar a prestação dos serviços e de reduzir os custos e o tamanho da máquina pública (BRESSER-PEREIRA, 2017).

Impulsionado pela necessidade de adaptação ao estado social, que visa ao atendimento dos interesses sociais e à garantia de direitos, com destaque para a Carta Magna de 1988, o governo se viu diante da imperatividade de atendimento a essas demandas, as quais já eram realidade em outras partes do mundo. Assim, o modelo burocrático se apresentou demasiadamente rígido e custoso ao Estado, representando um entrave ao processo de desenvolvimento, uma vez que se centrava na ideia de redução do tamanho do Estado como mecanismo de controle de recursos e de responsabilidades governamentais (BRESSER-PEREIRA, 2017; NETO, 2010).

Mas, para prover a máquina pública de eficiência com menos custos, foi preciso redefinir o papel da atuação do público com a implantação de uma administração gerencial, tornando-a capaz de ampliar seu envolvimento com diversas demandas sociais, embora não no nível desejado pela sociedade (BRESSER-PEREIRA, 2017).

Nesse momento, década de 1996, como parte das iniciativas do já extinto Ministério da Administração e Reforma do Estado (MARE), foi criado o concurso para premiação de experiências inovadoras na Administração Pública Federal que pretendia estimular a prática da inovação em órgãos e em instituições de governo. Ao longo do tempo, foram observadas iniciativas em diversas áreas de atuação do Estado, com destaque para as inovações de melhoria em processos de trabalho, revelando a orientação para a racionalização de processos e mostrando a necessidade de se fazer mais com menos recursos disponíveis (CAMÕES et al., 2017).

Destaca-se que, em 1998, a Constituição Federal foi alterada pela Emenda Constitucional n. 19, que acrescentou o princípio da eficiência na Administração Pública, revelando um marco legal de destaque para a orientação gerencial do Estado brasileiro (BRASIL, 1998).

Como apontou o estudo de Camões et al., (2017), destacado anteriormente, é necessário promover a inovação, contudo, deve-se compreendê-la dentro do contexto brasileiro e é preciso entender como deve se organizar o sistema de inovação para promover melhorias que impactem em resultados sociais, institucionais e de governo.

Em 2016, foi criada a Rede de Inovação do Setor Público (InovaGov), com o objetivo de revolucionar a forma de gestão dos projetos e serviços, estimulando a geração de ideias e as soluções criativas. Atualmente, essa rede é formada por 74 instituições do Setor Público, 20 do Setor Privado, 12 do Terceiro Setor e apenas quatro instituições acadêmicas, além dos pesquisadores independentes (BRASIL, 2019). O modelo do InovaGov segue a proposta da Quádrupla Hélice, que revisou a Hélice Tripla (Universidade - Indústria - Governo) e insere a participação da sociedade civil (MINEIRO et al., 2018).

O setor público e, de maneira mais ampla, os governos estão aprendendo a respeito da inovação e das formas de incentivá-la. O relatório preliminar da OCDE (2018b) para o Brasil aponta que nos últimos anos o setor público dedicou maior atenção à inovação, mas que ainda há um longo caminho a percorrer. 
Esse documento traçou um perfil do Brasil em termos de práticas de inovação. A compreensão de suas perspectivas históricas, seu nível atual e as possibilidades para o futuro foram informações basilares para o autoconhecimento do país/governo em relação ao tema. A abordagem sistêmica para o setor público é proposta como uma concepção adequada ao ambiente de mudanças e com diversos agentes que refletem necessidades de adaptação e de reorganização (OCDE, 2018b).

O que a população espera de seu governo; como políticos e agentes públicos podem atuar para promoverem a inovação; colocar a inovação como atividade que exorbita centros específicos e categorias especializadas; adaptar-se às mudanças e, também, promovê-las, são partes que dialogam para o estabelecimento de um sistema de inovação.

A partir das pesquisas e dos estudos utilizados para elaboração deste artigo, observou-se que o país necessita atuar no fortalecimento da cultura da inovação, de modo a fortalecer essa competência nuclear e promover essas práticas em todas as organizações no âmbito federal.

As barreiras apresentadas no Quadro 2 revelam a necessidade de ações mais integradas entre os órgãos de governo, a exemplo dos ministérios e instituições a eles vinculadas, de modo que a inovação não seja uma prática isolada ou tenha como estímulo apenas ações pontuais, como é o caso do concurso federal para premiar boas práticas.

Diante dos levantamentos aqui trazidos, não foi possível observar se, de fato, o governo federal comunica para as suas instituições que a inovação é um valor a ser perseguido como parte da cultura das organizações, a ser considerado na missão, na qualificação dos recursos humanos e, na prática, para contribuir na resolução de problemas e melhorar o desempenho de instituições dos diferentes setores. Nessa perspectiva de governo está se discutindo a proposta sistêmica (OCDE, 2018b), na qual todos devem estar alinhados com o objetivo da inovação.

\subsection{Caminhos, Barreiras e Perspectivas da Inovação no Serviço Público Brasileiro}

Klamb e Hoffman (2016) apresentaram fatores limitantes para a inovação nas organizações públicas, desde o modelo burocrático de gestão até a gestão contemporânea. Para aquelas organizações que mantêm estruturas burocráticas como modelo predominante, há condições para o desenvolvimento de barreiras à inovação, devido ao caráter impessoal que os comportamentos formais, baseados em normas e em regulamentos, geram. Essa estrutura rígida bloqueia as iniciativas criativas e a autonomia dos agentes em experimentar e em questionar as atuais práticas.

O estudo de Brandão e Bruno-Faria (2017) trouxe informações sobre os dirigentes de organizações públicas federais com o objetivo de demonstrar as principais barreiras para o processo de inovação que foram relacionadas e definidas. A pesquisa foi empírica, utilizando-se de documentos e de entrevistas. Para a seleção da amostra, foram utilizados documentos com casos premiados no Concurso de Inovação da ENAP e foi realizada uma análise dos sites para apoiar a caracterização da amostra, composta de respondentes ocupantes de nível estratégico.

Essa abordagem contribuiu para observação desses componentes limitadores da inovação, obtidos em níveis estratégicos das organizações, que é de onde se espera originar as principais diretrizes a serem divulgadas, incorporadas à cultura e postas em prática pelos colaboradores. Contudo, em muitos casos, há barreiras que não são facilmente gerenciáveis pela alta administração, conforme apresentado no Quadro 2. 
Quadro 2 - Definições constitutivas dos fatores que exercem o papel de barreiras à inovação em gestão

\begin{tabular}{|c|c|}
\hline Barreiras & Definições \\
\hline $\begin{array}{l}\text { Dificuldade de } \\
\text { articulação intersetorial }\end{array}$ & $\begin{array}{l}\text { Dificuldade de coordenação e articulação de políticas públicas de caráter } \\
\text { transversal e intersetorial que envolvem órgãos de diferentes setores. }\end{array}$ \\
\hline Restrições legais & $\begin{array}{l}\text { Exigências legais e normativas que geram obstáculos ao desenvolvimento } \\
\text { de novos procedimentos, produtos, serviços e políticas públicas. }\end{array}$ \\
\hline $\begin{array}{l}\text { Estrutura organizacional } \\
\text { verticalizada }\end{array}$ & $\begin{array}{l}\text { Modelo verticalizado de ordenamento e agrupamento de atividades e } \\
\text { recursos que geram estruturas hierárquicas rígidas e podem tornar o } \\
\text { processo de comunicação e de tomada de decisão lentos e ineficientes. }\end{array}$ \\
\hline $\begin{array}{l}\text { Resistência à inovação } \\
\text { e aversão ao risco }\end{array}$ & $\begin{array}{l}\text { Conjunto de hábitos, crenças, valores e atitudes compartilhados } \\
\text { pelos membros da organização e que se expressam pela maneira } \\
\text { como os indivíduos reagem negativamente à inovação. }\end{array}$ \\
\hline $\begin{array}{l}\text { Baixa capacidade técnica } \\
\text { de estados e municípios }\end{array}$ & $\begin{array}{l}\text { Baixo nível de qualificação técnica das equipes de estados e municípios } \\
\text { e infraestrutura física e tecnológica inadequadas ou insuficientes. }\end{array}$ \\
\hline $\begin{array}{l}\text { Rotatividade de } \\
\text { dirigentes }\end{array}$ & $\begin{array}{l}\text { Flexibilidade no sistema de seleção de dirigentes que permite } \\
\text { a rotatividade periódica de gestores e, por consequência, } \\
\text { dificulta a proposição e a implementação de inovações. }\end{array}$ \\
\hline $\begin{array}{l}\text { Diversidade social, } \\
\text { cultural e econômica } \\
\text { do país }\end{array}$ & $\begin{array}{l}\text { Pluralidade de condições culturais, sociais e de desenvolvimento político e } \\
\text { econômico da população em um país de dimensões continentais como o Brasil. }\end{array}$ \\
\hline $\begin{array}{l}\text { Recursos orçamentários } \\
\text { e financeiros limitados }\end{array}$ & $\begin{array}{l}\text { Insuficiência de recursos orçamentários e financeiros } \\
\text { para financiamento de inovações. }\end{array}$ \\
\hline $\begin{array}{c}\text { Faltas de incentivos } \\
\text { à inovação }\end{array}$ & Falta de apoio e suporte da organização à inovação. \\
\hline
\end{tabular}

Fonte: Brandão e Bruno-Faria (2017, p. 156)

Relacionando essas barreiras com aquelas apresentadas no Quadro 1, percebe-se as similaridades no que se refere, principalmente, às barreiras externas à organização, como a articulação intersetorial, as restrições legais, os recursos financeiros e orçamentários, pois o quadro mencionado tem como propósito mostrar as barreiras a serem consideradas para superar $e$ melhorar a atuação do governo. Consequentemente, com o enfrentamento daquelas barreiras, as instituições componentes do setor terão reflexos positivos, pois terão a chancela do governo para as iniciativas internas da inovação.

A partir do levantamento realizado no Quadro 2, há que se questionar quais medidas os dirigentes têm adotado para praticar inovação dentro das suas competências internas e mesmo diante das limitações, sendo este um indicador para nova pesquisa. Conhecer se os valores relativos à inovação estão sendo comunicados internamente, se há esforços para parcerias com universidades e outras instituições na qualificação dos recursos humanos, se existem incentivos e premiações patrocinados pela alta gestão e/ou outros, essas são informações que ajudarão a compreender melhor a inovação no serviço público federal e qual a interlocução entre instituições e o governo para um constructo contínuo da cultura da inovação e trocas mútuas.

Com base nas análises realizadas por Kenski (2011) acerca da inovação em diversas organizações, a orientação é que essa inovação seja processual, envolva todos os setores, seja fortalecida pela cultura e que seja exercida gestão sobre ela. Ou seja, quando a inovação é considerada um processo organizacional para a sua prática, consequentemente, será continuada 
e gerida, ao invés de ocorrer de forma isolada e sem coordenação. $\mathrm{O}$ autor destaca, ainda, que as instâncias deliberativas, a exemplo dos Conselhos de administração e fiscal, precisam apoiar a cultura da inovação, considerando que os riscos inerentes na decisão de investir na inovação não devem ser assumidos apenas pelos dirigentes (KENSKI, 2011).

Nesse particular, os colegiados deliberativos devem ser apoiadores dos gestores para patrocinar a inovação nas instituições públicas federais, especialmente na redução dos reflexos das barreiras relativas à resistência para a inovação e na aversão ao risco e à falta de incentivos à inovação, apresentados pelos dirigentes na pesquisa realizada por Brandão e Bruno-Faria (2017).

Com base nos autores aqui referenciados acerca do tema inovação no setor público, observou-se que nenhuma pesquisa apresentou resultados de instituições em que a inovação esteja presente na cultura e se apresente como um processo gerido pela organização. Nota-se uma oportunidade para a implementação da inovação organizacional que, conforme aponta o Manual de Oslo (OCDE, 2006), se refere a um novo método organizacional e tem reflexo na organização do local de trabalho. Ou seja, inicialmente, pode-se pensar a inovação nas organizações públicas federais, também, sob a perspectiva de desenvolvimento de novos métodos com impactos internos, de modo que sejam geridos e aperfeiçoados continuamente para incorporação à cultura. Esse processo pode facilitar o surgimento de outros tipos de inovação.

Destaca-se nesse processo de adequação das estruturas dessas instituições a relevância das pessoas. Elas precisam estar engajadas e podem oferecer soluções de inovação, muitas vezes, simples e de fácil aplicação. Não é apenas tarefa da alta gestão pensar em inovação, os colaboradores de toda a organização, quando incentivados, são capazes de tornar a gestão da inovação mais participativa, receptiva e com resultados positivos para o negócio, conforme defende Robinson e Schroeder (2016).

\section{Considerações Finais}

Para a compreensão da inovação e sua aplicação na gestão das organizações do setor público, foram utilizadas abordagens com visões de autores e de instituições oficiais para respaldar o tema aqui abordado. As principais orientações teóricas expostas apresentam a abordagem da organização guiada por ideias de Robinson e Schroeder (2016) e a abordagem da gestão do conhecimento, nela contida a orientação da empresa criadora de conhecimento (TAKEUCHI; NONAKA, 2008).

Entende-se que ambas as abordagens podem ser aplicadas nas organizações públicas federais, considerando que a primeira defende a participação de todas as pessoas no processo de inovação, abrindo espaço para as ideias e a resolução de problemas e com possibilidades de soluções muitas vezes simples e sem demanda por altos investimentos. A segunda tem forte impacto no desenvolvimento de uma cultura orientada para o conhecimento, quando a organização aprende a desenvolver as pessoas e se beneficiar com a contínua participação do capital humano.

Ambas as abordagens são compreendidas por este estudo como teorias de base, adicionais às ideias de Cavalcante e Cunha (2017), considerando-se a necessidade de desenvolvimento de uma cultura da inovação e de envolvimento de todos os colaboradores, podendo oferecer subsídios às organizações públicas para sedimentar as práticas no setor. 
Entende-se que a proposta da OCDE (2018b) para adoção de uma abordagem sistêmica da inovação no Brasil pode ser um fator de promoção de avanços, pois ter-se-á condições de uma orientação clara e uníssona do governo federal para as suas instituições e para seus servidores, podendo superar o estado de isolamento de muitas organizações públicas na agenda de inovação.

É consensual entre autores e instituições oficiais abordadas a relevância da cultura da inovação para atuação competitiva de uma organização. Na mesma medida, o setor público precisa orientar-se para a gestão da inovação como forma de devolver o atendimento aos interesses sociais, por meio da aplicação de práticas que promovam a eficiência do setor. Iniciativas do Governo Federal têm ampliado o tema da inovação sob diversos olhares, práticas e perspectivas, como o Concurso Inovação na Gestão Pública Federal, que vem se mostrando desde 1996 uma fonte rica de boas práticas, pesquisas e indicativo de estímulo às organizações públicas no desenvolvimento da gestão da inovação e do conhecimento, e a Rede InovaGov, que reúne diferentes atores da sociedade para fortalecimento da inovação no país.

Propõe-se a ampliação de ações para o concurso em que sejam premiadas iniciativas de inovação estimuladas dentro dos próprios órgãos. Sugere-se que a inovação não seja adotada em práticas pontuais e isoladamente em algumas instituições do Governo Federal, sendo realizado o questionamento sobre o nível de conhecimento dessa premiação em toda a Administração Pública Federal. Uma comunicação mais efetiva em todo o setor pode aumentar a participação e revelar práticas ainda não conhecidas. Outro ponto é sobre ir além de premiar, mas oferecer subsídios para que as organizações públicas federais inovem.

O concurso pode estar alinhado a uma diretriz geral de governo com informações claras, metas e recursos para que os agentes públicos possam caminhar em direção ao objetivo e buscar solucionar problemas que representam barreiras à eficiência. Esse direcionamento deve envolver toda a Administração Pública Federal e não estar limitado a alguns Ministérios e órgãos com maior vocação à inovação, dada a atividade específica em que atuam, uma vez que a gestão da inovação deve ser buscada por qualquer organização, independentemente de sua missão ou atividade.

A Rede InovaGov, por ser um conjunto de ações novas, criada em 2016, ainda precisa ampliar a participação de mais agentes pertencentes aos setores que a compõem, especialmente das instituições de ensino, uma vez que apenas quatro delas participam da rede.

Observou-se, também, que a continuidade de alguns estudos pode contribuir para melhor compreensão da inovação no setor público federal brasileiro. A pesquisa de Brandão e Bruno-Faria (2017) pode ser ampliada para verificar quais medidas os dirigentes, incluindo instâncias deliberativas, estão adotando para a implementação da inovação. Pois, tomando por base a abordagem sistêmica proposta pela $\operatorname{OCDE}$ (2018, p. 4), "não há lugar para espectadores".

O estudo, também, verificou a ausência de modelo ou de design organizacional que representasse a inovação em sua perspectiva de processo gerido, tendo mais evidências sobre as iniciativas pontuais que refletem boas práticas de gestão, mas que não estão diretamente ligadas às exigências do governo federal. Compreende-se que, inicialmente, o governo brasileiro deve fortalecer a cultura da inovação, incorporar a missão de suas instituições e preparar o capital humano. 
Como limitação para o estudo, podem ser destacadas as dificuldades na busca por documentos técnicos oficiais disponíveis para consulta acerca da inovação no serviço público brasileiro.

\section{Referências}

BIRKINSHAW, J.; HAMEL, G.; MOL, M. J. Management innovation. Academy of Management Review, [S.I.], v. 33, n. 4, p. 825-845, 2008.

BOWREY, Graham; HUI, Freda; SMARK, Ciorstan. An 1831 discussion on New Public Management. Accounting History, [S.l.], v. 22, n. 3, p. 370-386, August, 2017. Disponível em: https://journalssagepub-com.ez357.periodicos.capes.gov.br/doi/10.1177/1032373216686086. Acesso em: 24 set. 2019.

BRANDÃO, Soraya Monteiro; BRUNO-FARIA, Maria de Fátima. Barreiras à inovação em gestão em organizações públicas do governo federal brasileiro: análise da percepção de dirigentes. In: CAVALCANTE, Pedro et al. (org.). Inovação no setor público: teoria, tendências e casos no Brasil. Brasília: IPEA, 2017. p. 145-164.

BRASIL. Emenda Constitucional n. 19, de 4 de junho de 1998. Disponível em: http://www. planalto.gov.br/ccivil_03/Constituicao/Emendas/Emc/emc19.htm. Acesso em: 3 set. 2019.

BRASIL. InovaGov. 2016. Disponível em: www.inovagov.com.br. Acesso em: 5 set. 2019.

BRASIL. Governo cria rede de inovação no setor público federal. Brasília: Ministério do Planejamento Orçamento e Gestão. [2019]. Disponível em: http://www.planejamento.gov.br/ assuntos/logistica-e-tecnologia-da-informacao/noticias/governo-cria-rede-de-inovacao-no-setorpublico-federal. Acesso em: 5 set. 2019.

BRESSER-PEREIRA, Luiz Carlos. Reforma gerencial e legitimação do estado social. In: Revista de Administração Pública, Rio de Janeiro, v. 51, n 1, p. 147-156, jan.-fev. 2017. Disponível em: http://www.scielo.br/pdf/rap/v51n1/0034-7612-rap-51-01-00147.pdf. Acesso em: 2 set. 2019.

BRESSER-PEREIRA, Luiz Carlos. Reforma da nova gestão pública: agora na agenda da América Latina. Revista do Serviço Público, [S.l.], ano 53, n. 1, jan.-mar. 2002. Disponível em: https:// repositorio.enap.gov.br/bitstream/1/1919/1/2002\%20Vol.53\%2cn.1\%20Bresser.pdf. Acesso em: 24 set. 2019.

CAMÕES, Marizaura Reis de Souza et al. Inovação na gestão pública federal: 20 anos do prêmio inovação. In: CAVALCANTE, Pedro et al. (org.). Inovação no setor público: teoria, tendências e casos no Brasil. Brasília: IPEA, 2017. p. 95-117.

CASETTI, Marjorie Morales. Nueva gestión pública en Chile: orígenes y efectos. Revista de Ciencia Política, [Chile], n. 2, p. 417-438, 2014.

CAVALCANTE, Pedro; CUNHA, Bruno Queiroz. É preciso inovar no governo, mas por quê? In: CAVALCANTE, Pedro et al. (org.). Inovação no setor público: teoria, tendências e casos no Brasil. Brasília: IPEA, 2017. p. 15-32.

CHRISTENSEN, Clayton M. O dilema da inovação: quando as novas tecnologias levam empresas ao fracasso. São Paulo: M. Books do Brasil, 2012. 
CLAD - CENTRO LATINO AMERICANO DE ADMINISTRAÇÃO PARA O DESENVOLVIMENTO. Uma nova gestão pública para a América Latina. Revista do Serviço Público, [S.I.], v. 50, n. 1, p. 121-144, 1998. Disponível em: https://revista.enap.gov.br/index.php/RSP/article/view/343. Acesso em: 24 set. 2019.

COMISSÃO EUROPEIA. Powering European Public Sector Innovation: Towards a New Architecture. Report of the Expert Group on Public Sector Innovation, Directorate General for Research and Innovation, Innovation Union, European Commission, Brussels, 2013. Disponível em: https://ec.europa.eu/research/innovation-union/pdf/psi_eg.pdf. Acesso em: 29 ago. 2019.

KEELEY, Larry et al. Dez tipos de inovação: a disciplina da criação de avanços de ruptura. São Paulo: DVS Editora, 2015.

KENSKI, Victor Wolowski. Inovação, organização e aprendizagem organizacional. Revista Científica Hermes, [S.1.], v. 5, p. 23-37, 2011. Disponível em: http://www.redalyc.org/articulo. oa?id=477648585002. Acesso em: 21 set. 2019.

KLUMB, Rosangela; HOFFMANN, Micheline Gaia. Inovação no Setor Público e Evolução dos Modelos de Administração Pública: o Caso do TRE-SC. Cadernos Gestão Pública e Cidadania, [S.l.], v. 21, n. 69, p. 86-102, 2016.

LEÓN, Lorena Rivera; SIMMONDS, Paul; ROMAN, Laura. Trends and Challenges in Public Sector Innovation in Europe. Bruxelas: DG Enterprise, dezembro de 2012. Disponível em: https:// www.technopolis-group.com/wp-content/uploads/2014/06/1447_INNOERATREND-2011-12.pdf. Acesso em: 22 set. 2019.

MINEIRO, Andréa A. da Costa et al. Da hélice tríplice à quíntupla: uma revisão sistemática. Economia e Gestão, Belo Horizonte, v. 18, n. 51, set.-dez. 2018.

NETO, Pedro Thomé de Arruda. Reforma do Estado e evolução dos modelos de gestão pública no Brasil: a democracia deliberativa como fundamentos de uma nova administração pública constitucional. Revista de Direito Administrativo, Rio de Janeiro, v. 253, p. 133-158, jan. 2010. Disponível em: http://bibliotecadigital.fgv.br/ojs/index.php/rda/article/view/8050. Acesso em: 24 set. 2019.

NONAKA, Ikujiro. A empresa criadora de conhecimento. In: TAKEUCHI, Hirotaka; NONAKA, Ikujiro (org.). Gestão do conhecimento. Porto Alegre: Bookman, 2008. p. 39-53.

OCDE - ORGANIZAÇÃO PARA COOPERAÇÃO DO DESENVOLVIMENTO ECONÔMICO. Manual de Oslo. 3. ed. [S.l.]: OCDE, 2006. Disponível em: https://www.finep.gov.br/images/apoio-efinanciamento/manualoslo.pdf. Acesso em: 18 agos. 2019.

OCDE - ORGANIZAÇÃO PARA COOPERAÇÃO DO DESENVOLVIMENTO ECONÔMICO. Manual de Oslo. 4. ed. . [S.l.]: OCDE, 2018a. Disponível em: https:/www.mctic.gov.br/mctic/export/sites/ institucional/indicadores/detalhe/Manuais/OCDE-Manual-de-Oslo-4-edicao-em-ingles.pdf. Acesso em: 29 set. 2019.

OCDE - ORGANIZAÇÃO PARA COOPERAÇÃO DO DESENVOLVIMENTO ECONÔMICO. O sistema de inovação do serviço público do Brasil: conclusões preliminares da OCDE. Paris: OCDE, 2018 b.

OLIVEIRA, Leonardo Ferreira de; SANTOS JÚNIOR, Carlos Denner dos. Inovações no setor público: uma abordagem teórica sobre os impactos de sua adoção. In: CAVALCANTE, P. et al. (org.). Inovação no setor público: teoria, tendências e casos no Brasil. Brasília: IPEA, 2017. p. 34-42. 
PEDROSA, Tamires. Os caminhos para a inovação no serviço público. 2019. Disponível em: https://administradores.com.br/artigos/os-caminhos-para-a-inovacao-no-setor-publico. Acesso em: 19 set. 2019.

PLONSKI, Guilherme Ari. Inovação em transformação. Estudos Avançados, [S.I.], v. 31, n. 90, 2017. Disponível em: http://www.scielo.br/scielo.php?script=sci_issuetoc\&pid=0103$401420190002 \& \operatorname{lng}=$ pt\&nrm=iso. Acesso em: 19 set. 2019.

ROBINSON, Alan G.; SCHROEDER, Dean M. Organização guiada por ideias: inovação a partir de todas as pessoas. São Paulo: M. Books, 2016.

SANTOS, Adriana B. A. dos; FAZION, Cíntia B.; MEROE, Giuliano P. S de. Inovação: um estudo sobre a evolução do conceito de Schumpeter. Caderno de Administração, [S.l.], v. 5, n.1, 2011. Disponível em: https://revistas.pucsp.br/caadm/article/view/9014/6623. Acesso em: 18 ago. 2019.

SCHUMPETER, J. A. Theory of Economic Development. Tradução de Maria Sílvia Possas. São Paulo; Cambridge: Harvard University Press, 1934.

SCHUMPETER, J. A. Theory of Economic Development. Tradução de Maria Sílvia Possas. São Paulo: Nova Cultural Ltda., 1997.

SILVA et al. Modelos para gestão da inovação: revisão e análise da literatura. Production. [S.l.], v. 24, n. 2, p. 477-490, Apr.-June, 2014.

TAKEUCHI, Hirotaka; NONAKA, Ikujiro. Teoria da criação do conhecimento organizacional. In:

TAKEUCHI, Hirotaka; NONAKA, Ikujiro. (org.). Gestão do conhecimento. Porto Alegre: Bookman, 2008. p. 54-90.

TIGRE, Paulo Bastos. Gestão da inovação: a economia da tecnologia do Brasil. 7. Reimpressão. Rio de Janeiro: Elsevier, 2006. il.

\section{Sobre os Autores}

\section{Bartolomeu das Neves Marques}

E-mail: bartolomeumarques@yahoo.com.br

Aluno do Mestrado Profissional em Propriedade Intelectual e Transferência de Tecnologia para Inovação (PROFNIT/ IFBA).

Endereço profissional: Rua Emídio dos Santos, s/n, Barbalho, Salvador, BA. CEP: 40301-015.

\section{Ângela Maria Ferreira Lima}

E-mail: angela.lima@gmail.com

Doutorado em Energia e Ambiente pela Universidade Federal da Bahia.

Endereço profissional: Rua Emídio dos Santos, s/n, Barbalho, Salvador, BA. CEP: 40301-015.

\section{André Luis Rocha de Souza}

E-mail:profandre.ifba@gmail.com

Doutorado em Engenharia Industrial pela Universidade Federal da Bahia.

Endereço profissional: Rua Emídio dos Santos, s/n, Barbalho, Salvador, BA. CEP: 40301-015. 


\section{Marcio Luis Valença Araújo}

E-mail:maraujo.valenca@gmail.com

Doutorado em Modelagem Computacional e Tecnologia Industrial pelo SENAI, Departamento Regional da Bahia.

Endereço profissional: Rua Emídio dos Santos, s/n, Barbalho, Salvador, BA. CEP: 40301-015. 